\title{
Experimental Comparison of the MIG and Friction Stir Welding Processes for AA 6005 Aluminium Alloy
}

\author{
S. Caruso ${ }^{1, a}$, D. Campanella ${ }^{2, b}$, S. Candamano ${ }^{3, c}$, C. Varrese ${ }^{1, d}$, F. Crea ${ }^{3, e}$, \\ L. Filice ${ }^{1, f}$, D. Umbrello ${ }^{1, g^{*}}$ \\ ${ }^{1}$ Department of Mechanical, Energy and Management Engineering, University of Calabria, Rende \\ CS 87036, Italy.
}

${ }^{2}$ Department of Manufacturing, Production and Management Engineering, University of Palermo, Palermo PA 90128, Italy.

${ }^{3}$ Department of Environmental and Chemical Engineering DIATIC, University of Calabria, Rende CS 87036, Italy.

aserafino.caruso@unical.it, 'bdavide.campanella@unipa.it, 'sebastiano.candamano@unical.it,

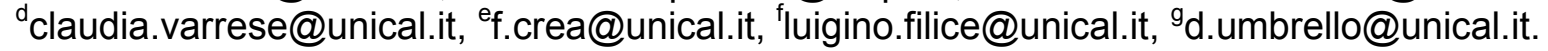

Keywords: Frictions Stir Welding (FSW), Metal Inert Gas (MIG) welding, Aluminum alloy.

\begin{abstract}
In this study, the mechanical properties of welded joints of AA 6005 aluminum alloy obtained with friction stir welding (FSW) and conventional metal inert gas welding (MIG) are studied. FSW welds were carried out on a semi-automatic milling machine. The performance of FSW and MIG welded joints were identified using tensile and bending impact tests, as far as the environmental aspects are also included in the discussion. The joints obtained with FSW and MIG processes were also investigated in their microstructure. The results indicate that, the microstructure of the friction stir weld is different from that of MIG welded joint. The weld nugget consists of small grains in FSW than those found in MIG weld. Taking into consideration the process conditions and requirements, FSW and MIG processes were also compared with each other to understand the advantages and disadvantages of the processes for welding applications of studied Al alloy. Better tensile and bending strength were obtained with FSW welded joints.
\end{abstract}

\section{Introduction}

The natural qualities of aluminium and its alloys are positive factors for designers, manufacturers and industrial users due to their unique mechanical, electrical, thermal, and recycling properties as lightness, corrosion resistance, etc. Aluminum alloys are one of the widely used material for several industrial applications: aerospace (aircraft primary structures), automotive (chassis, engine blocks, radiators), marine (lightness and corrosion resistance), rail (lighter structures, resistance and durability), building (extruded, sheet-rolled form for window frames), mechanical industry and engineering, energy distribution (good electrical conductivity), sports and leisure (refrigerators, CD coatings, trailers).

Because of this technical importance, a large number of designers and technologists have been employed to investigate and to optimize the manufacturing processes of aluminum alloys; a particular interest has been given to the welded joints [1-6]. In this work, the attention was focused on friction stir welding (FSW) and conventional metal inert gas welding (MIG).

Friction stir welding (FSW) was invented in 1991 as a solid state welding process, enjoying worldwide interest because of its advantages over traditional joining techniques. In the FSW process, a special rotating tool travels down the length of contacting metal plates, with a continual hot working action, creating a plastically deformed zone that is stirred into a solid-phase weld on the trailing side of the welding head pin. At the same time, the thermo-mechanical affected zone is produced by friction between the tool shoulder and the workpiece and by the contact of the material with the tool edges, inducing plastic deformation: it is considered that the formability of FS-welded material is influenced by FSW parameters [7-13]. 
Metal inert gas (MIG) welding is an arc welding process in which additional metal is molten with a part of workpiece, by Joule effect and an electric arc. In this process a inert gas, generally argon based gas, is used as plasma for electric arc and to avoid the contamination of the molten metal by oxygen and nitrogen. In this context, and taking into account the series of disadvantages when traditional welding processes are applied to aluminum alloys, this work aims to compare the mechanical properties of FSW with conventional arc-welding method metal inert gas welding (MIG).

\section{Experimental Plan}

Both welding processes were tested for same joints typology. In detail, three different weld seams were produced in the whole experimental campaign: a) butt welding between single skin plates with a thickness of $4,5 \mathrm{~mm}, \mathrm{~b}$ ) overlapped edges welding between double skin plates with a thickness of $4,5 \mathrm{~mm}$ and a distance between the plates of $50 \mathrm{~mm}$ and c) overlapped edges welding between a curved profile suitably worked and single skin plate with a thickness of $4.5 \mathrm{~mm}$. The material used in this study was a commercially available AA-6005 aluminum alloy commonly utilized in the railway sector.

Friction Stir Welding (FSW). The FSW was carried out by using a semiautomatic milling machine. The sheets were placed within the milling volume and their edges were combined and fixed with a suitable equipment (Fig. 1).
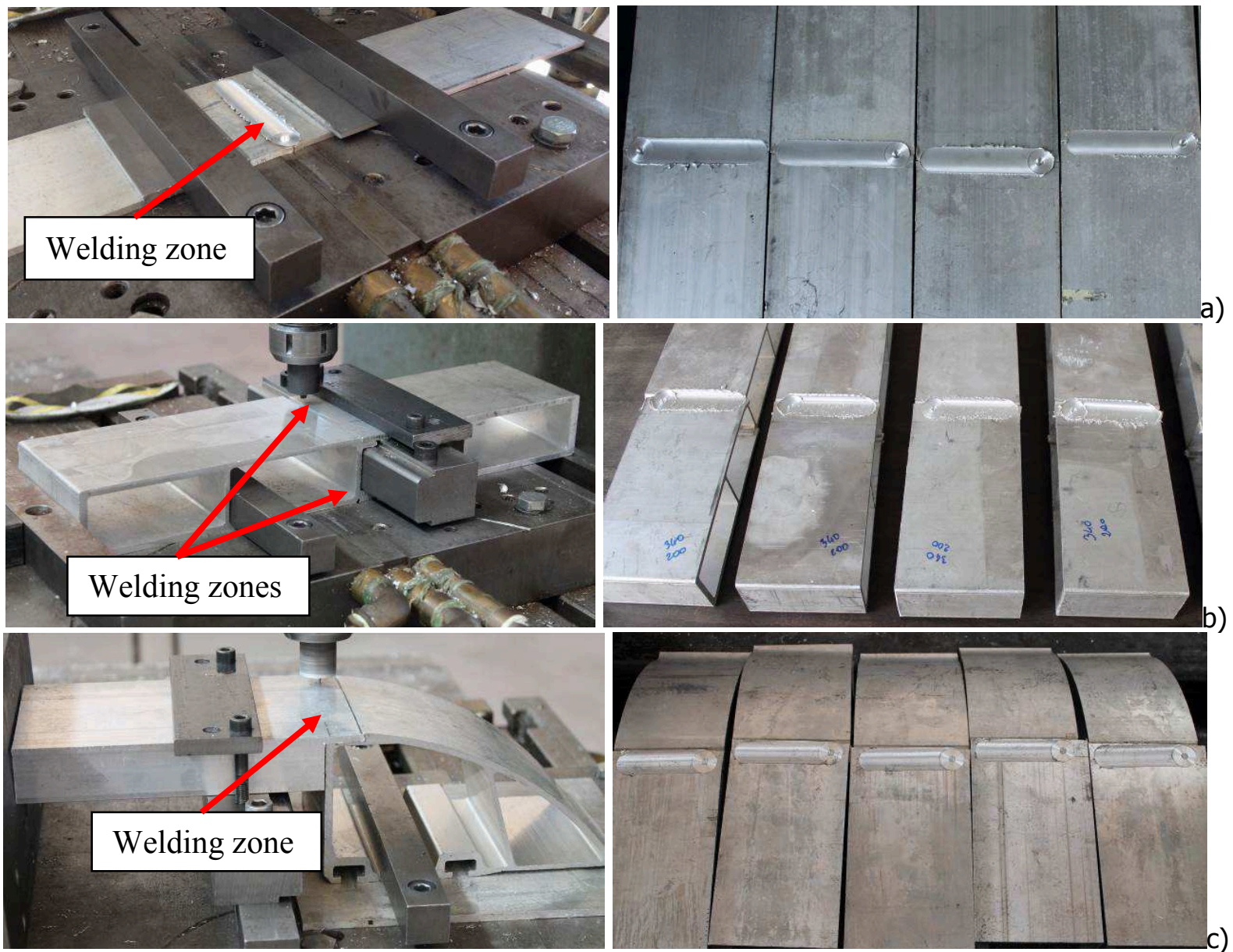

Figure 1. Experimental set-up used for the FSW and welded parts for the three different joined parts: a) butt welding, b) overlapped edges welding of flat parts and c) overlapped edges welding with curved part.

The same tool was used for the different welding typologies; it can be divided in two main parts which are the so defined shoulder with a diameter of $16 \mathrm{~mm}$ and the probe whose main dimensions are reported in Fig. 2. 


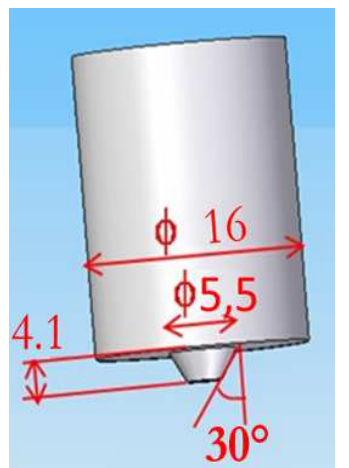

Figure 2. Friction Stir Welding Tool.

The experiments were conducted with rotational speeds $(\mathrm{R})$ of $700 \mathrm{rpm}$, and translational (traverse) velocities of $100 \mathrm{~mm} / \mathrm{min}$.

Metal Inert Gas (MIG). The seam welds were produced by using a MIG FRONIUS TransPuls 5000 sinergic welding machine with argon 5.0 gas at a flow rate of $151 . \mathrm{min}^{-1}$ and a pressure of 4 bar. The welds were carried out by the same operator. The produced weld seams for each analyzed configuration are reported in Fig. 3.
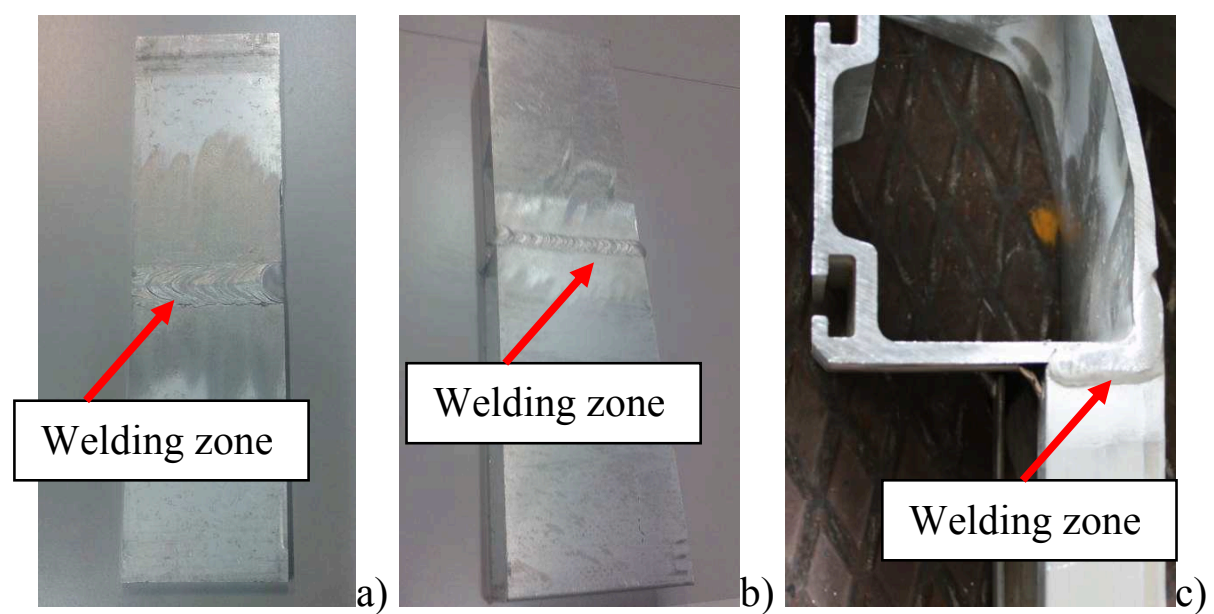

Figure 3. Experimental results with $M I G$ welding for the three different joined parts: a) butt welding, b) overlapped edges welding of flat parts and c) overlapped edges welding with curved part.

\section{Experimental Results and Discussion}

Tensile, shear and three-point bending tests were performed on welded parts to evaluate and to compare the performance of FSW and MIG welding processes. More in particular, each analyzed weld seam typology was investigated with one of the above reported tests. Finally, the microstructure of both FSW and MIG welded region were investigated.

Tensile Test. The butt welding between single skin plates were tested by tensile tests. Specimens, according to the standards, were properly obtained by the joined plates. The investigation was carried out by an Instron machine, with a load capacity of $100 \mathrm{kN}$; here, the specimens were clamped with suitable terminal blocks at two horizontal crossbars.

The experiments were performed with two ram speeds of 0.1 and $1.0 \mathrm{~mm} / \mathrm{sec}$, positioning the welded joints at the center of the work-volume (Fig. 4). Each test was carried out three times to take into account their repeatability. 

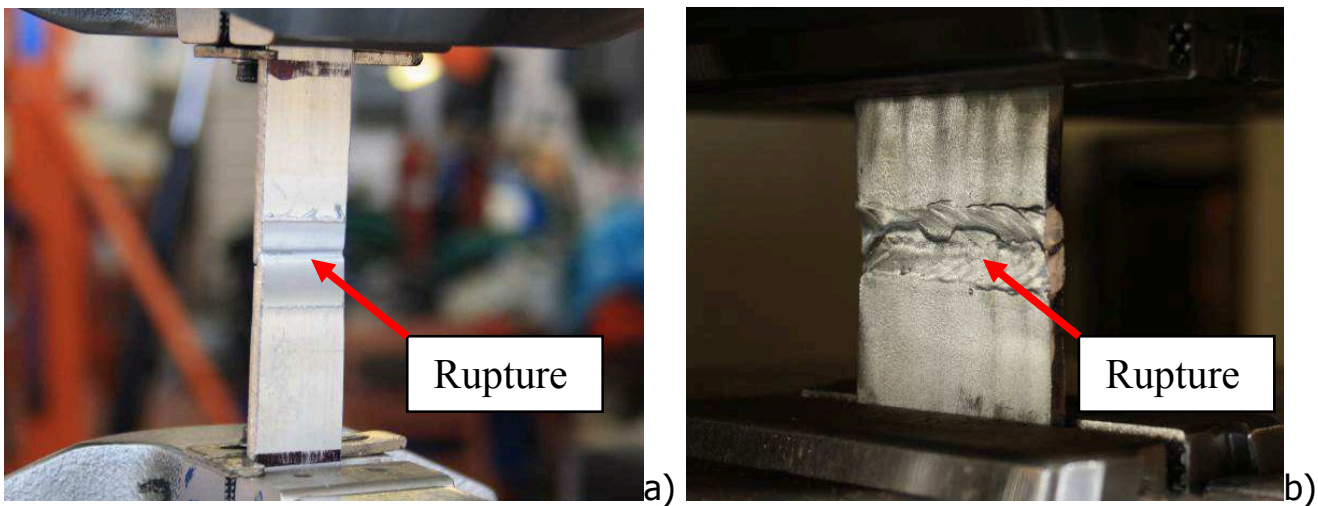

Figure 4. Tensile test for a) FSW and b) MIG welding.

The obtained results were properly analyzed and the comparison between FSW and MIG was reported in Fig. 5; here, good repeatability of the tests can be noticed.

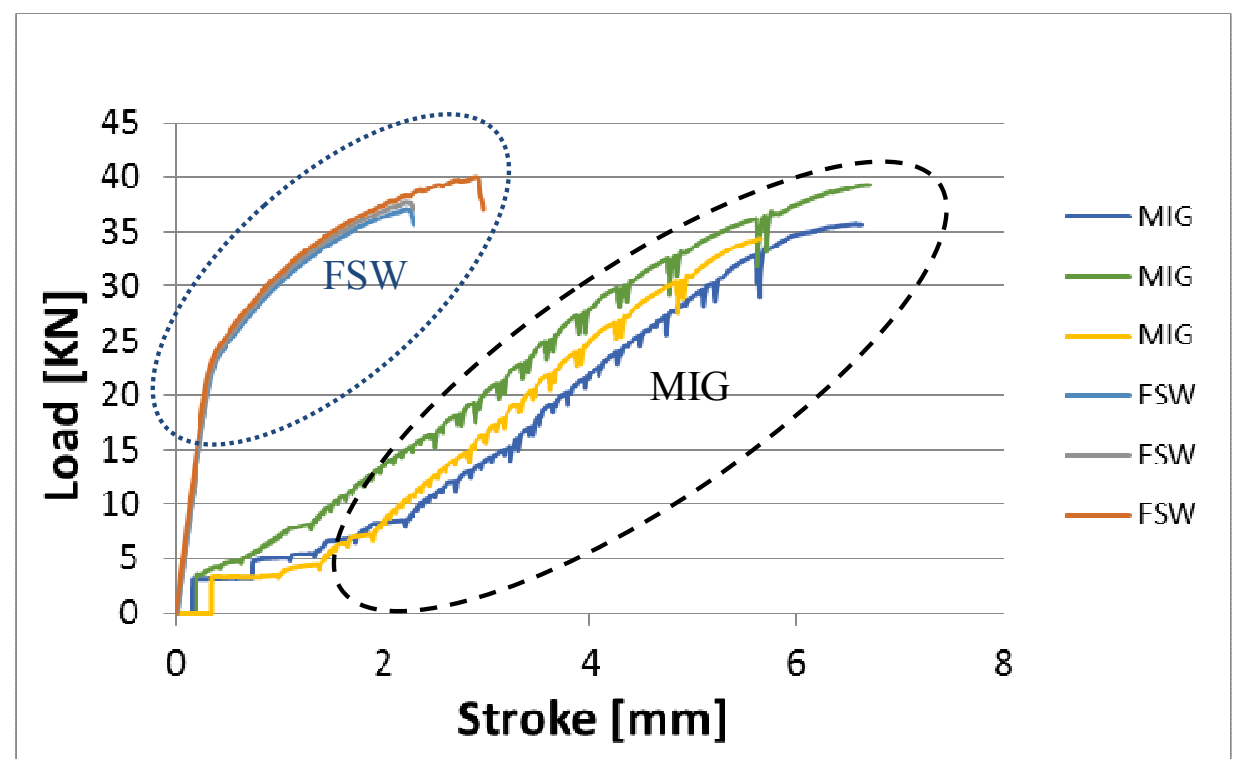

Figure 5. Tensile strength of FSW and MIG welding: $V=0.1 \mathrm{~mm} / \mathrm{sec}$.

Considering the ram movement, MIG welding shows a more ductile behavior than FSW, with maximum strokes that is three times bigger than the ones for FSW at the same working conditions. Looking at the load trend, no significant discrepancies were observed between the two welding techniques. The results highlighted in Fig. 5 refer to the ram speed of $0.1 \mathrm{~mm} / \mathrm{s}$ but same considerations were also observed for the specimens tested at $1.0 \mathrm{~mm} / \mathrm{sec}$.

Bending Test. The overlapped edges welding between double skin plates were tested by three-point bending tests (Fig. 6). Also in this case the experiments were performed with two different ram speeds of 0.1 and $1.0 \mathrm{~mm} / \mathrm{sec}$ and each case was investigated with a repeatability of three times.
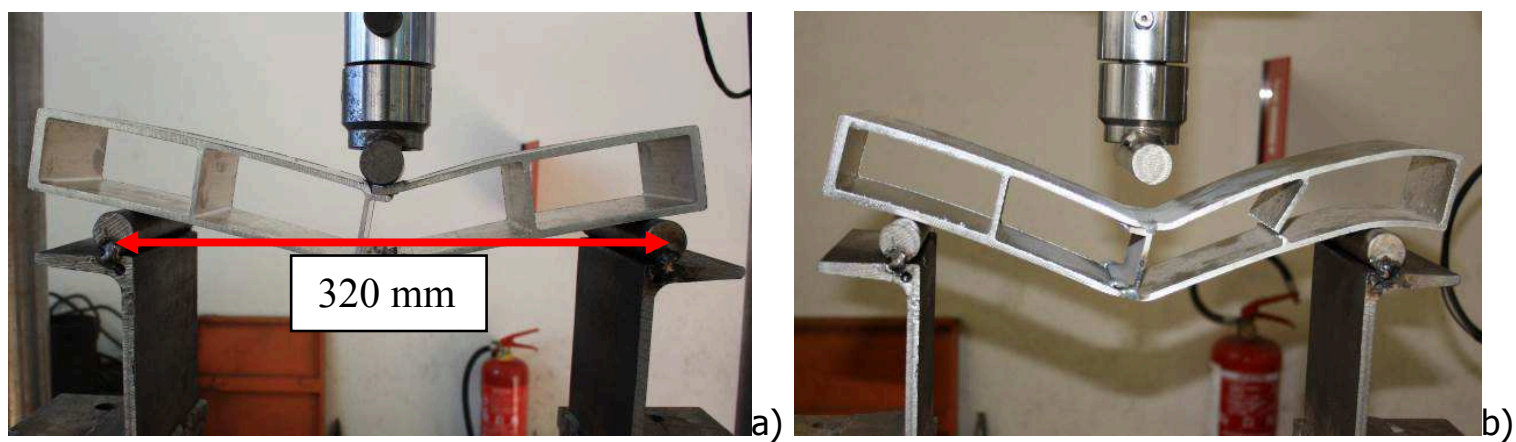

Figure 6. Three-Point bending test for a) FSW and b) MIG welding. 
The obtained results were properly analyzed and the comparison between FSW and MIG welding was reported in Fig. 7.

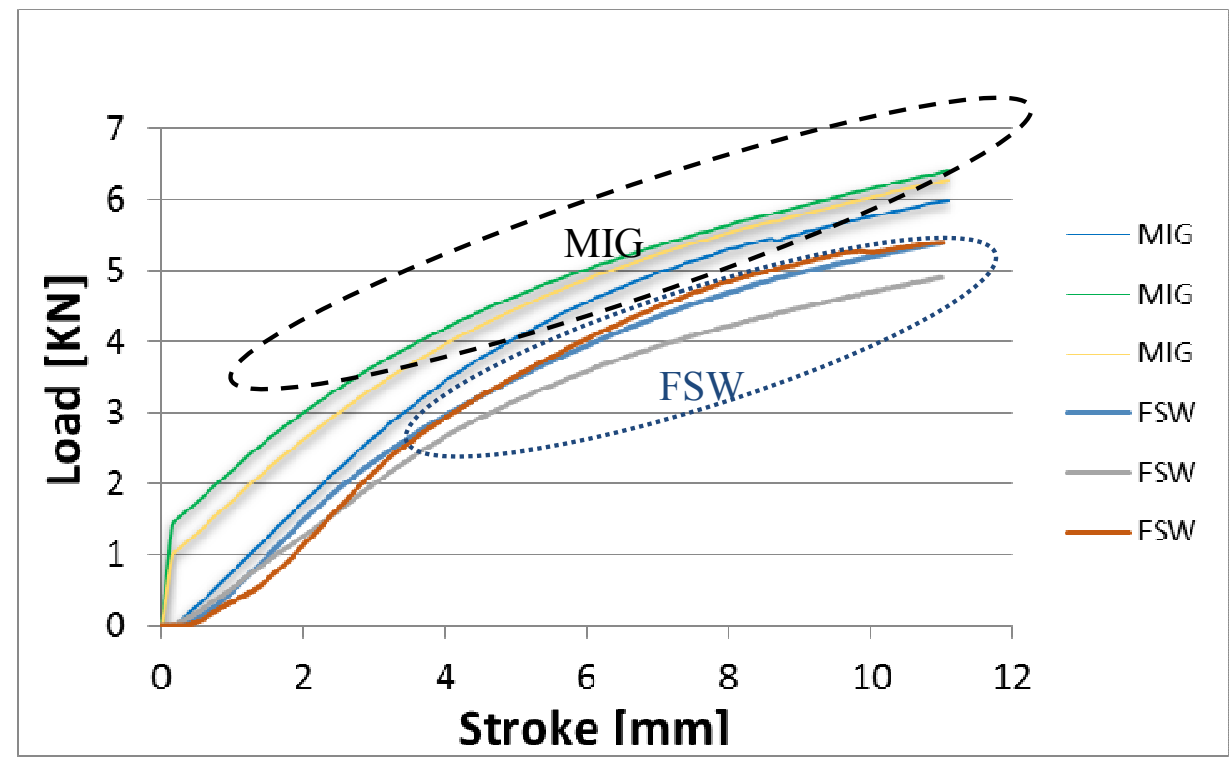

Figure 7. Bending strength of FSW and $M I G$ welding: $V=0.1 \mathrm{~mm} / \mathrm{sec}$.

As can be observed both FSW and MIG welding show the same behavior with no significant difference. More in detail, a slight reduction of strength is registered for the FSW due to the length of the welded joint that in FSW is shorter for the space required to the tool at the beginning and the end of the welded joint.

Furthermore, the two welded joints showed the same behavior if the stroke is taken into account. However, it has to be said that the test typology did not permit to give bending component on the welded joints, and, therefore, the welded joints are able to resist at outstanding stroke values. Finally, no influence has to be ascribed to the ram velocity as observed for the tensile tests.

Shear Test. The overlapped edges welding between a curved profile suitably worked and a single skin plate were tested by shear tests. Also in this case the experiments were performed with two different ram speeds of 0.1 and $1.0 \mathrm{~mm} / \mathrm{sec}$ with a repeatability of three times for each investigated case (Fig. 8).
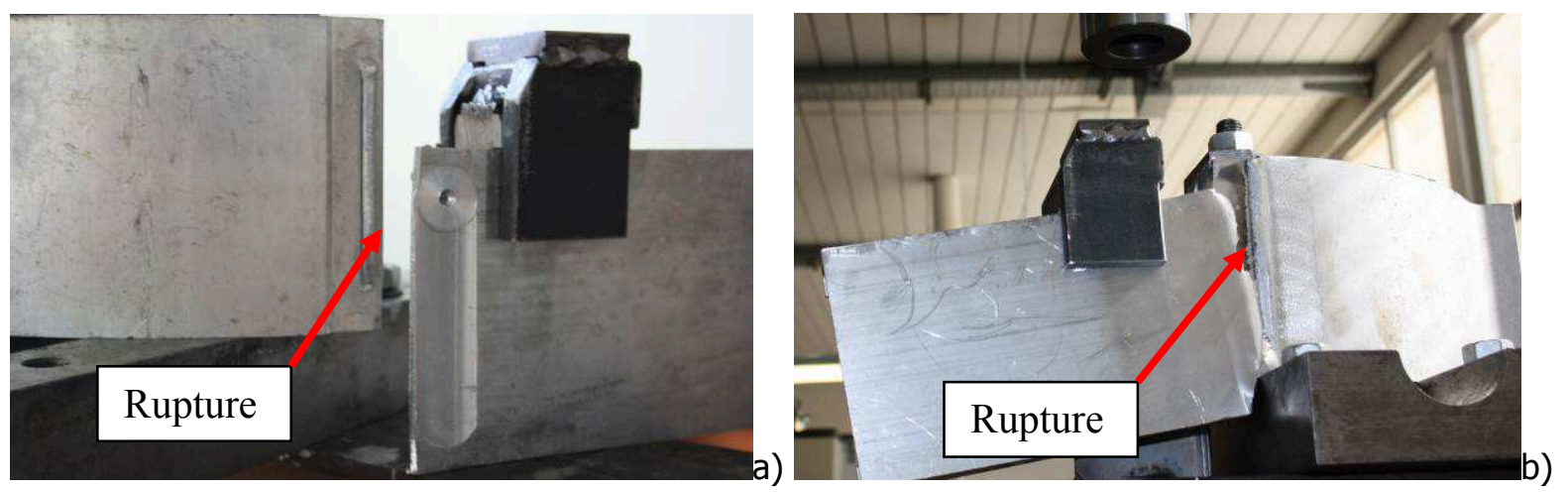

Figure 8. Shear test for a) FSW and b) MIG welding.

The obtained results for this test typology were reported in Fig. 9. 


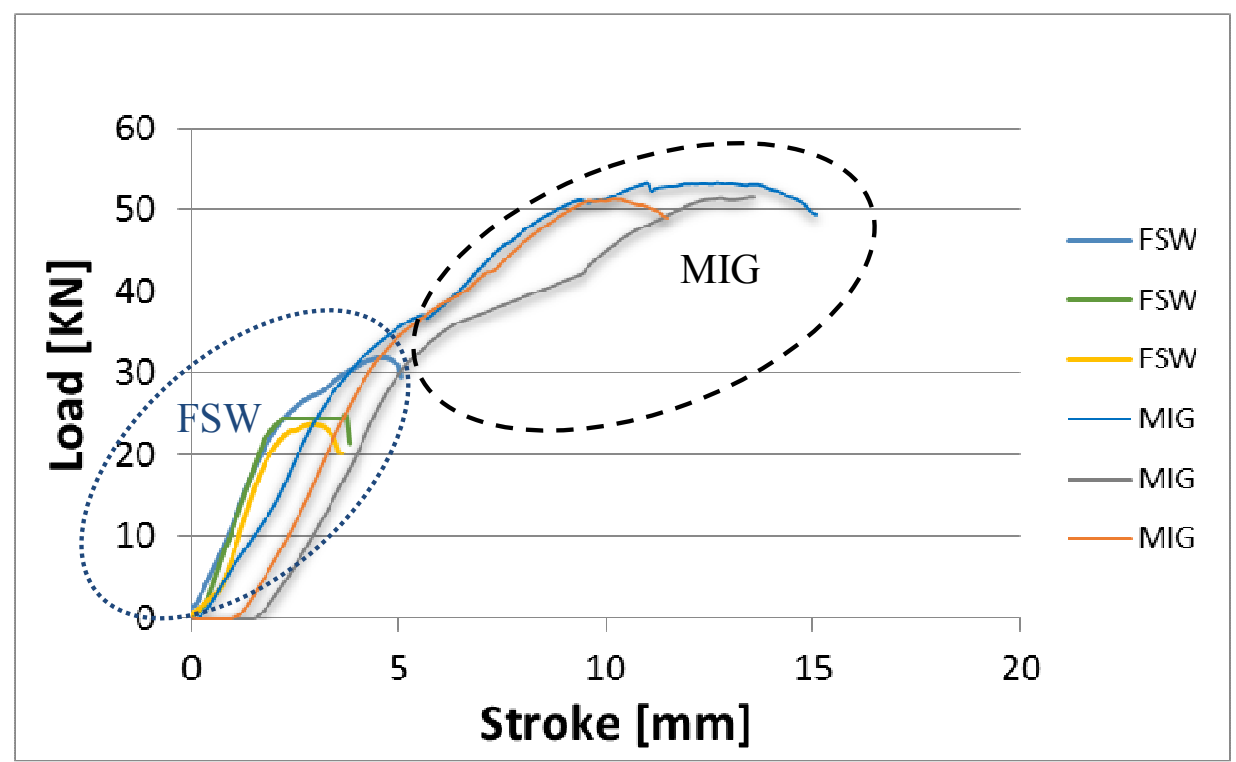

Figure 9. Shear strength of FSW and MIG welding: $V=0.1 \mathrm{~mm} / \mathrm{sec}$.

An evident difference between FSW and MIG welding is registered. In particular the welded joint obtained with FSW showed a minor resistance in terms of maximum load and stroke. This is due to the quality of the welded joint that was not produced in a perfect way for the particular design of the experiment. In fact the tool didn't reach a right depth resulting in a no perfect quality of the joint.

Concerning the obtained results, it is important to highlight that the process parameters used for the FSW process were not optimized but set as suggested in literature when same sheet thickness and tool-workpiece materials were used. As far as tensile strength is concerning, FSW showed good results when compared with MIG; in fact, considering tensile and bending strength, no significant discrepancies were observed when the load trend is considered. In contrast, the joint ductility (i.e. elongation at break) obtained by FSW shower lower properties when compared to the MIG welds. This behavior can be improved by doing a FSW process parameters optimization.

Microstructural Analysis. Specimens were sliced from various cross-sections in the welded zones of both FSW and MIG welding and they were prepared with metallurgical polishing and chemical etching (Keller's reagent: $190 \mathrm{ml} \mathrm{H}_{2} \mathrm{O}, 5 \mathrm{ml} \mathrm{HNO}_{3}, 3 \mathrm{ml} \mathrm{HCL}$ and $2 \mathrm{ml} \mathrm{HF}$ ).

Optical microscope and Scanning Electron Microscope (SEM) were used to characterize and compare the microstructures of the welded zones obtained with FSW and MIG welding (Fig. 10).

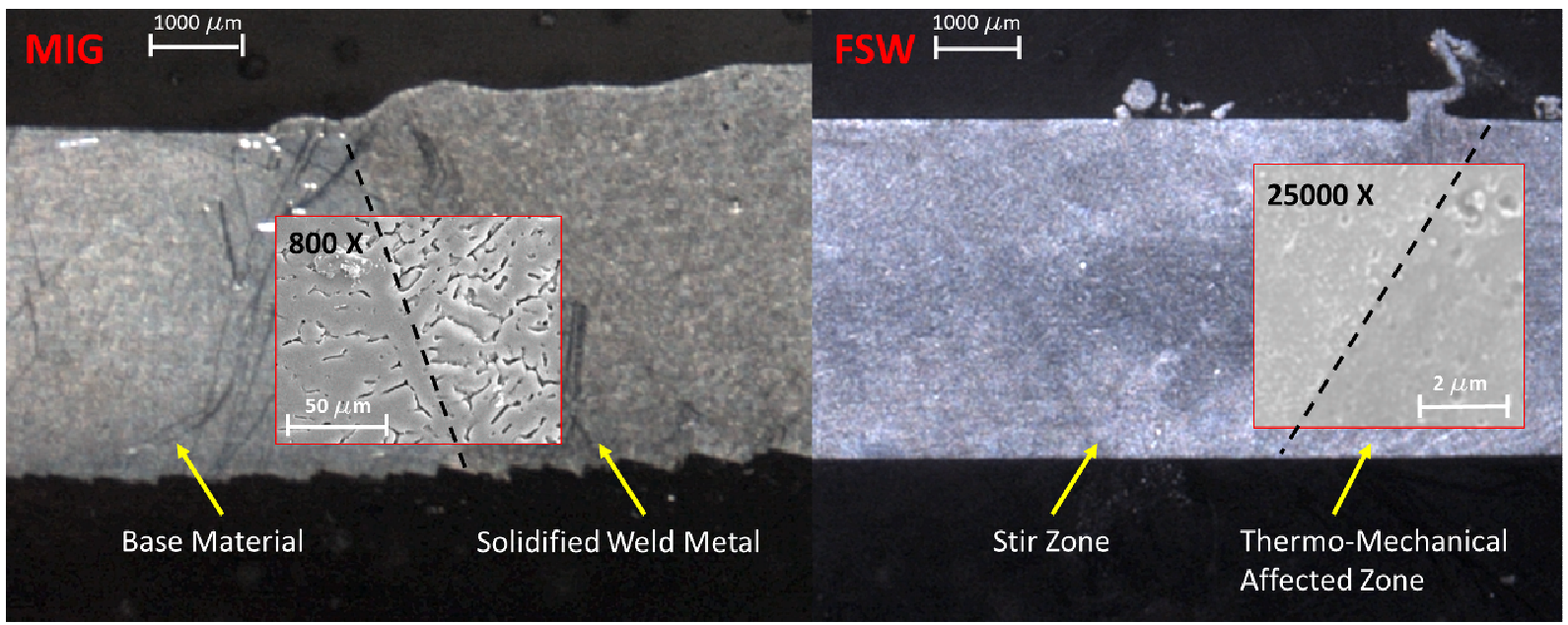

Figure 10. Cross section of FSW and MIG welding, showing the different welded zone. 
In Fig. 10 are showed the microstructures observed in the four analyzed zones. In particular a zoom of $800 \mathrm{X}$ is reported for the welded zone of the MIG welding while a zoom of $25000 \mathrm{X}$ is reported for the welded zone of the FSW.

As can be observed the solidified weld metal of MIG shows an high density dendritic structure mainly due to the fast heating of base metal and fast cooling of molten metal due to welding heat [1]. A different structure was observed for FSW, in fact it is showed that the Thermo-Mechanical Affected Zone is characterized by recovered grains containing an high dislocation density, while in the stir zone, a very fine equiaxed grains occur due to the dynamic recrystallization $[3,4]$.

\section{Conclusions}

In this paper a comparison of the MIG and FSW for AA 6005 Aluminium Alloy was studied. It was found that for tensile test the MIG shows a more ductile behavior than FSW, with a maximum strokes that is three times bigger than the ones for FSW at the some working conditions.

Furthermore, while for the bending test a no significant difference was registered comparing FSW and MIG on the contrary an evident difference of resistance occurs when the shear resistance is analyzed. Finally, the microstructural analysis showed a high density dendritic structure in the weld metal of MIG due to the rapid heating and cooling of the welding zone, while a fine equiaxed grains occur in the weld metal of FSW due to the dynamic recrystallization.

\section{References}

[1] M.K. Kulekci, E. Kaluc, A. Sik, "Experimental comparison of MIG and friction stir welding processes for EN AW-6061-T6 (Al Mg1 Si Cu) aluminium alloy", Arabian Journal for Science and Engineering, 35-1B,2010, pp. 321-330.

[2] K.M. Haitham, "A comparative study between friction stir welding and metal inert gas welding of 2024-T4 aluminum alloy”, ARPN Journal of Engineering and Applied Sciences 6/11, 2011, pp. $36-40$.

[3] J.Q. Su, T.W. Nelson, R. Mishra, M. Mahoney, "Microstructural investigation of friction stir welded 7050-T651 aluminium”, Acta Materialia, 51/3, 2003, pp. 713-729.

[4] K.V. Jata, S.L. Semiatin, "Continuous dynamic recrystallization during friction stir welding of high strength aluminum alloys", Scripta Materialia, 43/8, 2000, pp. 743-749.

[5] G. Liu, L.E. Murr, C-S Niou, J.C. McClure, F.R. Vega, "Microstructural aspects of the frictionstir welding of 6061-T6 aluminum", Scripta Materialia, 37/3, 1997, pp. 355-361.

[6] O.V. Flores, C. Kennedy, L.E. Murr, D. Brown, S. Pappu, B.M. Nowak, J.C. McClure, "Microstructural issues in a friction-stir-welded aluminum alloy", Scripta Materialia, 38/5, 1998, pp. 703-708.

[7] G. Liu, L.E. Murr, C-S Niou, J.C. McClure, F.R. Vega, Scripta Materialia, 37, 1997, p. 355.

[8] Y.S. Sato, H. Kokawa, M. Enomoto, S. Jogan, Metall. Materialia, Trans. 30/A, 1999, p. 2429.

[9] S. Benavides, Y. Li, L.E. Murr, D. Brown, J.C. McClure, Scripta Materialia, 41, 1999, p. 809.

[10] K.V. Jata, S.L. Semiatin, Scripta Materialia, 43, 2000, p. 743.

[11] G.S. Frankel, Z. Xia, Corrosion, 22, 1999, p. 139.

[12] P.S. Pao, S.J. Gill, C.R. Feng, K.K. Sankaran, Scripta Materialia, 45, 2001, p. 605.

[13] T. Hirata, T. Oguri, H. Hagino, T. Tanaka, S.W. Chung, Y. Takigawa, K. Higashi, "Influence of friction stir welding parameters on grain size and formability in 5083 aluminium alloy. Materials Science and Engineering, 456/1-2, 2007, pp. 344-349. 